\title{
Here a Game, There a Game: classification, gamification, and retrieval learning
}

\author{
O. Borchert, G. Hokanson, A. Peruri, B.M. Slator
}

Department of Computer Science, North Dakota State University

\begin{abstract}
A multi-user classification system is used in a classroom setting. Groups of students take samples, then collaborate on conducting experiments and building classification trees. Students are motivated by a point scoring system as they build the trees: formative gamification. Once the trees are completed they are exchanged between groups. The trees are constructed with structural commonality enabling them to act as content for template-based identification games: summative gamification.
\end{abstract}

Keywords: innovative materials, teaching and learning experiences, emerging technology practices, gamification

\section{Introduction}

CIRCLE (Collaborative Identification, Retrieval, and Classification Learning Environment) uses mobile technology to support teams of students who gather content for classroom projects that identify and classify real world objects such as plants and animals or rocks and minerals. The classification trees produced are used to populate identification and classification game templates that students can then play to rehearse through practiced retrieval. Retrieval learning postulates the act of retrieving knowledge in multiple different ways leads to better learning outcomes (Karpicke, 2012).

In decades past, identification and classification learning took place through the use of flash cards. These paper-based practices evolved into identification and classification games during the Internet age (Kids Know It Network 2013; Crimson Trails 2013; Jensen 2013; Kinder Web Games 2013). There are two primary drawbacks to these methods. While they have been studied extensively (Nist \& Joseph 2008; Kornell 2009), they are not informed by modern educational practice. It has been shown that students are not simply empty vessels, meant to be filled, but actively construct their knowledge (Richardson 2003; Bransford et al. 2000). In addition, these games are fairly static and designed completely by their developers.

Game templates offer an avenue for improvement on these static games. An example of a game with a template is GeoGuessr (Coldwell 2013). In this game, students see a Google Street View image and get points for identifying where on the world they are located. Less technological game template solutions include trivia games and typing tutors.

While these pre-defined templates are entertaining, user generated content provides a unique method of motivating individuals. Studies identifying motivations of individuals creating user generated content show a variety of reasons for its development (Daugherty et al. 2008; Leung 2009). Rather than using content developed by instructors, we place content gathering into user hands. We harness this motivation to teach students the identification and classification task. 


\section{Methods}

CIRCLE implements retrieval learning through the use of games in two primary ways. First, students gather content, identify specimens, and build classification structures. Students score points in this phase by contributing to the content structures. We call this formative gamification. Second, game templates are created by developers. These templates specify the rules for a particular game, while remaining context independent. Students reinforce their learning by playing these games which are generated by integrating specific content into the game template. We call this summative gamification.

\begin{tabular}{|c|c|c|c|c|c|c|}
\hline POINTS & Gathered & Elaborated & Identified & Constructed & Played & Total \\
\hline & 1 & 4 & 0 & 1 & 3 & 9 \\
\hline & 4 & 5 & 1 & 0 & 1 & 11 \\
\hline
\end{tabular}

Figure 1: Students score points which provide motivation and individual accountability. The player in the fourth row has not gathered any specimens, but has 12 points, the most on the team.

\section{Implementing Classification Acquisition}

There are five primary student activities in CIRCLE. Content acquisition, trait elaboration, hypothesis formation, and tree construction are independent activities while game play is part of all the others. The system tracks students and records their use of the system, time on task during each activity, and interactions with each other. Students are assigned collaborative roles according to the activities. Throughout each of these stages, points associated with these activities are kept as a running score, see figure 1 . We call this formative gamification.

\section{Content Acquisition}

Gatherers primarily collect photographs that are uploaded to a central server for inspection by the team. Camera phones with GPS are preferred, since this simplifies logging the time and place the specimens are collected.

\section{Trait Elaboration}

Elaborators suggest traits to observe or experiments to conduct as a means towards identification. Gatherers perform these experiments and observations, returning to the logged location if necessary. The team can also vote on experiments they feel are most important to completing the identification.

\section{Tree Construction}

Classification trees are constructed where traits and experiments are shown as branches of the tree, and specimens are the leaves. Students in the role of 'constructors' take suggestions from team members on how to arrange the structure leading to a dichotomous key. 


\section{Hypothesis Formation}

Hypotheses are offered by team members in the 'identifier' role as to the general classification or precise identity of the specimens. In the absence of an expert, such as a classroom teacher, hypotheses are voted on in a parimutuel-like system, where a probability of identification is associated with each competing classification.

\section{Game Play}

A knowledge base of logging data is collected during the four phases, see table 1 . This data is used to populate game templates, described below. Players select a game to play and their collected content is used to create a game unique to their information, including all experiments and observations suggested and performed, all results of these experiments and observations, the moderation scores of the elaborations, all hypotheses suggested whether correct or not, the identification of each individual specimen, and the specific set of tests required to identify the specimens.

Table 1. Data gathered in CIRCLE by stage

\begin{tabular}{|c|c|}
\hline Stage & Data Gathered \\
\hline Gathering & $\begin{array}{l}\text { - Text description of the specimen } \\
\text { - Multimedia artifacts of the specimen (ie audio, video, and images) } \\
\text { - Text description of the location of the specimen } \\
\text { - GPS coordinates of the specimen (if available) }\end{array}$ \\
\hline Elaborating & $\begin{array}{l}\text { - Name of the elaboration } \\
\text { - } \text { Instructions for how to perform the elaboration } \\
\text { - } \text { Basic description of the elaboration. } \\
\text { - Results of the elaboration (i.e. Number, text, picture, audio clip, } \\
\text { and/or video) }\end{array}$ \\
\hline Classifying & $\begin{array}{l}\text { - Paths of elaborations and results that lead to particular specimens } \\
\text { - All individual actions taken to construct the tree }\end{array}$ \\
\hline Identifying & $\begin{array}{l}\text { - Correct and incorrect hypotheses suggested by players } \\
\text { - Reasons for choosing a particular hypothesis } \\
\text { - Votes indicating which hypothesis players feel is the correct one }\end{array}$ \\
\hline Other & $\begin{array}{l}\text { - Real-time conversations though a chat interface } \\
\text { - Asynchronous communication through a bulletin board system } \\
\text { - Client-side actions that players have taken (e.g. mouse clicks, } \\
\text { buttons pressed) }\end{array}$ \\
\hline
\end{tabular}

\section{Example}

After a gatherer has submitted photographs of a rocky outcrop, an elaborator might suggest a 'hardness' experiment using a 'glass plate' to classify a mineral. Team members moderate the experiments and voting takes place to reach team consensus on the important trait elaborations, such as an acid test be performed on a neighboring rock. The constructors take these pieces and interactively shape them into a classification tree. Then student identifiers suggest "Limestone" for a particular node 
of the tree as a hypothesis based on the experimental results. The combination of these efforts represents the learning outcomes of the team

\section{Select Experiments Game}

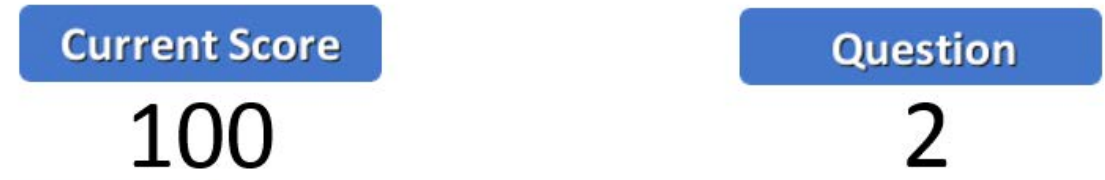

\section{Name}

Flowering Dogwood

\section{Multimedia}

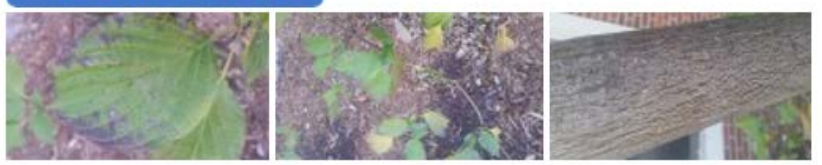

\section{Description}

short, small trunk, small leaves

\section{Select Experiments}

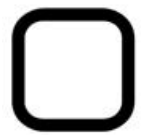

Branching Pattern

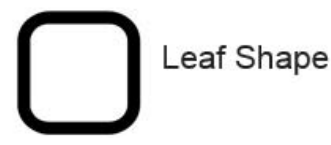

Figure 2: A mock-up of the Select Experiments Game. The name, multimedia, description, and experiments to select are changed for each question and match specific specimens the group has identified. In this example, a player must click the empty boxes, selecting whether they feel that leaf shape or branching pattern is more important to identifying Flowering Dogwood.

\section{Implementing Gaming Templates}

When classification trees are completed and validated they become input to game templates. These templates are essentially a system of game rules as predetermined by developers. Context is then applied to these templates based on the knowledge base developed during formative gamification.

The "Select Experiments" game and the "Identification" game are two template examples. During the "Select Experiments" game (see figure 2), students are given a description, name, and multimedia artifacts related to a previously identified specimen. They gain and lose points based on their selection of appropriate experiments and observations to identify that specimen. In the identification game, students are given the description, location, multimedia artifacts, and relevant experimental and observational results and receive points for each correctly identified specimen.

\section{Results and Discussion}

CIRCLE holds great promise at improving student understanding of the classification and identification tasks. Future development will focus on the creation of more game 
templates. In addition to the "Select Experiments" game and the "Identification" game many more opportunities for game templates exist. Some ideas include:

- Multiplayer - Players take turns selecting experiments or identifying specimens.

- Timed - Players are timed while they select experiments and identify specimens. The fastest time with the highest accuracy gets the most points.

- Memory Game - The system places gathered multimedia specimens onto cards with two of each specimen face down. Players need to find the two cards that contained the same specimen. The fewest number of moves would receive the most points. This could be combined with a multiplayer template such that the individual who found the most pairs wins.

- Classi-Caching - (see Geocaching) - Users attempt to find other examples of the same specimen out in the real world. If they find an example, they mark the location in the game. Other players need to go to that location and either agree or disagree that it is the same as the original specimen. Points are given for the number of matching specimens found and level of agreement on whether the specimen matches the in-game specimen.

- Audio hide and seek - In this audio-only template, students would search for a sound that was similar to a specimen that was already collected. Players receive points for how close the sounds matched.

\section{Conclusions and Future Work}

CIRCLE was used by both STEM experts and undergraduate ecology students in 2014 (Borchert et al. 2015). The actions of each participant was logged to accurately capture their sequence. In addition, the participants were observed and formative feedback was solicited. Finally, a 10-item System Usability Scale (SUS 1986) and 4item open ended questionnaire was administered as a means of gathering information about the ease of use of CIRCLE.

The open ended questions included "What things were good about CIRCLE? Why?", "What was bad about CIRCLE? Why?", "What should be changed about CIRCLE?”, and included an area to add additional comments. In the SUS instrument, users expressed an opinion on a five point Likert scale from Strongly Agree to Strongly Disagree. The responses to the open ended questions were then correlated with individual SUS questions. For example, SUS question \#5 is " 9 . I found the various functions in CIRCLE were well integrated" and user comments included (referring to using the color red as a visual cue in CIRCLE) "Red prompts for what to do next"

By contrast, SUS question \#6 is "I thought there was too much inconsistency in CIRCLE" which prompted one user to add "Unable to go back and change things", and another to suggest "add home button". A total of about 20 concrete and implementable suggestions were provided.

The next version of CIRCLE will address many of the 20 suggestions offered by the pilot study group, and our next experiment will administer another SUS questionnaire, with the responses tracked by SUS question number. In this way, we can methodically track and measure the improvements in the next version using changes in SUS scores.

Future development will focus on improving usability, so that players learn to love this innovative approach towards retrieval learning. 


\section{References}

Borchert, O., Slator, B. M., \& Hokanson, G. (2015). Lessons Learned in the Development of a Collaborative Learning Environment Designed to Educate Students on the Creation of User-generated Classification Structures. Proceedings of the Eighth International Conference on e-Learning and Innovative Pedagogies. Common Ground Publishing: Santa Cruz, CA. November 2-3.

Bransford, J. D., Brown, A. L., \& Cocking, R. R. (2000). How People Learn: Brain, Mind, Experience, and School. National Academy Press: Washington, DC.

Coldwell, W. (2013). Where in the world am I? The addictive mapping game that is GeoGuessr. The Independent. Retrieved from http://www.independent.co.uk/lifestyle/gadgets-and-tech/features/where-in-the-world-am-i-the-addictive-mappinggame-that-is-geoguessr-8641265.html on January 26, 2015.

Crimson Trails (2013). Geobirds. Retrieved from http://geobirds.com/play on September 9, 2013.

Daugherty, T., Eastin, M., \& Bright, L. (2008). Exploring Consumer Motivations for Creating User-Generated Content. Journal of Interactive Advertising, 8(2).

Geocaching (2000). http://en.wikipedia.org/wiki/Geocaching. Accessed 30 January 2015

Jensen, M. (2013). The Anatomy Game (Web Anatomy II). Retrieved from http://msjensen.cehd.umn.edu/webanatomy_archive/game/ on September 9, 2013.

Karpicke, J. D. (2012). Retrieval-Based Learning: Active Retrieval Promotes Meaningful Learning. Current Directions in Psychological Science, 21(3), 157163. doi: $10.1177 / 0963721412443552$

Kids Know It Network (2013). Identify Rock Types Game. Retrieved from http://www.kidsgeo.com/geology-games/rocks-game.php on August 26, 2013.

Kinder Web Games (2013). Letter Learning Game. Retrieved from http://kinderwebgames.com/a.html on September 9, 2013.

Kornell, N. (2009). Optimising learning using flashcards: Spacing is more effective than cramming. Applied Cognitive Psychology, 23(9), 1297-1317.

Leung, L. (2009). User-generated content on the internet: an examination of gratifications, civic engagement and psychological empowerment. New Media \& Society, 11(8), 1327-1347. doi: 10.1177/1461444809341264

Fielding, R. (2000). Architectural Styles and the Design of Network-based Software Architectures (Doctoral Dissertation). Retrieved from: http://www.ics.uci.edu/ fielding/pubs/dissertation/top.htm

Nist, L., \& Joseph, L. M. (2008). Effectiveness and Efficiency of Flashcard Drill Instructional Methods on Urban First-Graders' Word Recognition, Acquisition, Maintenance, and Generalization. School Psychology Review, 37(3), 294-308.

Richardson, V. (2003). Constructivist Pedagogy. Teachers College Record, 105(9), 1623-1640. doi: 10.1046/j.1467-9620.2003.00303.x

SUS (1986). System Usability Scale. Retrieved from http://www.usability.gov/howto-and-tools/methods/system-usability-scale.html on January 28, 2015. 